Check for updates

Cite this: RSC Adv., 2019, 9, 19844

Received 18th March 2019

Accepted 11th June 2019

DOI: 10.1039/c9ra02086a

rsc.li/rsc-advances

\section{Comprehensive study on the degradation of ochratoxin A in water by spectroscopic techniques and DFT calculations $\dagger$}

\author{
Iris Cagnasso, (D) ab Glauco Tonachini, (DD c Silvia Berto, (D) *c Agnese Giacomino, (D) ${ }^{d}$ \\ Luisa Mandrile, (D) a Andrea Maranzana (D) *c and Francesca Durbiano (iD) a
}

\begin{abstract}
Ochratoxin A (OTA) is one of the most important dietary risk factors and is classified as a possible carcinogen to humans. Assessing the conditions to remove it from foodstuffs in a simple and effective way is of the utmost importance. OTA behaviour in water in the $\mathrm{pH}$ range 1.0-12.5 was elucidated to investigate the conditions for irreversible toxicity inactivation of OTA. The results indicate that four forms, from neutral to trianionic, intervene depending on the $\mathrm{pH} . \mathrm{p} K_{\mathrm{a} 1,2}$ were rigorously established by independent spectroscopic techniques to overcome the scarcity of literature. Then, Density Functional Theory (DFT) calculations were used to determine the most probable degradation mechanism and this was confirmed by fluorescence spectroscopy. At pH 12.5, hydrolyzation of the lactone ring starts in less than one hour, but only after two hours does the degradation process lead to fragmentation. After one week this process is not yet completed. The reaction products occurring upon re-acidification were also investigated. OTA degradation is still reversible if acidic conditions are promptly restored, yielding again a hazardous molecule. However, degradation becomes irreversible after fragmentation. This finding suggests proceeding with due caution if a base is exploited to remove the toxin.
\end{abstract}

\section{Introduction}

Ochratoxin A (OTA) is a potent mycotoxin that severely affects animal and human health. It is produced by the secondary metabolisms of Aspergillus and Penicillium species contaminating a large variety of alimentary commodities. ${ }^{\mathbf{1 - 5}}$ Since it is considered one of the most important chronic dietary risk factors, the International Agency for Research on Cancer has classified OTA as a possible carcinogen to humans. ${ }^{6}$ The European Food Safety Authority set a tolerable weekly intake of $120 \mathrm{ng} \mathrm{kg}{ }^{-1}$ body weight $^{7-10}$ and maximum levels of OTA in foodstuffs were established by the Commission Regulation (EC) no. 1881/2006. ${ }^{11}$ Immunochemical methods, ${ }^{12-15}$ liquid chromatography coupled to fluorescence spectroscopy ${ }^{14,16-20}$ and mass spectrometry ${ }^{15,20,21}$ are commonly used for OTA determination. OTA, i.e. $\mathrm{N}$-[[(3R)-5-

${ }^{a}$ Metrology for Quality of Life Division, Istituto Nazionale di Ricerca Metrologica, Strada Delle Cacce 91, 10135 Torino, Italy

${ }^{b}$ Department of Applied Science and Technology, Politecnico di Torino, Corso Duca Degli Abruzzi 24, 10129 Torino, Italy

${ }^{c}$ Chemistry Department, Università di Torino, Via Giuria 7, 10125 Torino, Italy. E-mail: andrea.maranzana@unito.it; silvia.berto@unito.it

${ }^{d}$ Drug Science and Technology Department, Università di Torino, Via Giuria 9, 10125 Torino, Italy

$\dagger$ Electronic supplementary information (ESI) available: Spectra, emission-excitation matrices, DFT energetics, figures of the transition structures, optimized geometries and all examined reactions. See DOI: 10.1039/c9ra02086a chloro-8-hydroxy-3-methyl-1-oxo-7-isochromanyl]carbonyl]-3phenyl-L-alanine, ${ }^{22}$ consists of a dihydroisocumaric ring amidelinked to L-phenylalanine. ${ }^{23}$

In this work comprehensive description of OTA behaviour in aqueous solutions in the $\mathrm{pH}$ range 1.0-12.5 was carried out to provide useful information for further toxicological studies of one of the most dangerous and diffused natural foodstuff toxins.

In aqueous solution, OTA shows three levels of proton dissociation in the $\mathrm{pH}$ range $1.0-8.0$ (Fig. 1) ruled by the characteristic acid dissociation constants $\left(\mathrm{p} K_{\mathrm{a} 1,2}\right)$. The neutral form is present under acidic conditions, increasing the $\mathrm{pH}$ the phenylalanine carboxylic group loses a proton (monoanionic form), and the phenolic group loses a second proton at neutral $\mathrm{pH}$ (dianionic form).

Table 1 shows the $\mathrm{p} K_{\mathrm{a} 1,2}$ of OTA reported in articles where the authors determined them experimentally. The literature on this topic is scarce and generally old. The variability of the reported values is not negligible and the experimental description is often careless.

The scope of this work is to investigate the protonation equilibria of OTA and the conditions of irreversible toxicity deletion of the toxin due to $\mathrm{pH}$ and time effects only.

The $\mathrm{p} K_{\mathrm{a} 1,2}$ were estimated by UV-Vis absorption spectrophotometry and fluorescence spectroscopy with stoichiometric and chemometric approach, respectively. In this study, the collection and the analysis of data were carefully detailed, 


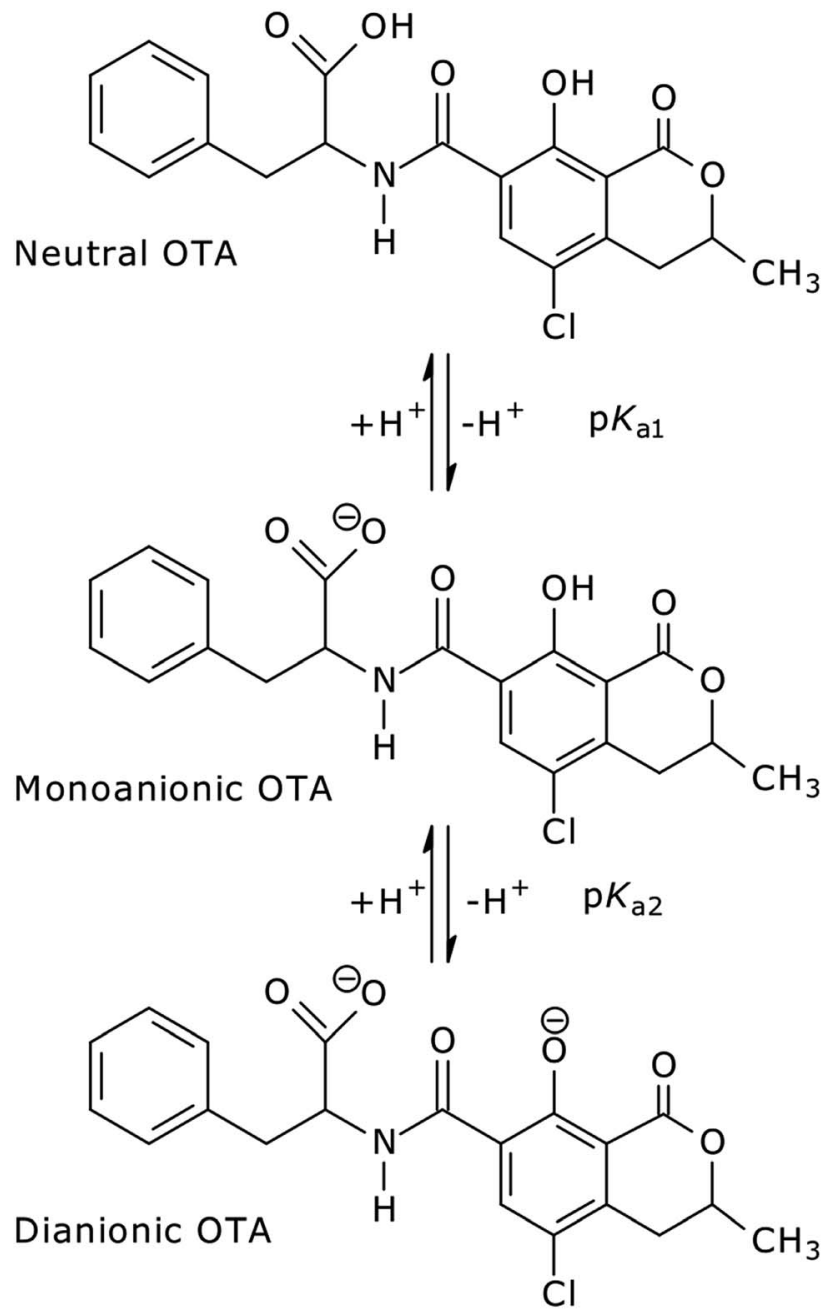

Fig. 1 OTA structures in aqueous solution in acidic to neutral $\mathrm{pH}$ range.

Table $1 \mathrm{p} K_{\mathrm{a}}$ values of OTA from literature

\begin{tabular}{|c|c|}
\hline Reference & Value \\
\hline & $\mathrm{p} K_{\mathrm{a} 1}$ \\
\hline \multirow[t]{2}{*}{ Uchiyama et al. $(1985)^{24}$} & 4.4 \\
\hline & $\mathrm{p} K_{\mathrm{a} 2}$ \\
\hline Gillman et al. $(1999)^{25}$ & 7.0 \\
\hline Xiao et al. $(1996)^{26}$ & $7.0 \pm 0.02^{a}$ \\
\hline Marquardt $(1992)^{27}$ & $7.05-7.1$ \\
\hline Uchiyama et al. $(1985)^{24}$ & 7.3 \\
\hline Chu et al. $(1972)^{28}$ & $7.05-7.10^{b}$ \\
\hline Chu et al. $(1971)^{29}$ & $7.04^{c}$ \\
\hline Pitout $(1968)^{30}$ & 7.1 \\
\hline
\end{tabular}

compared to older works. Thanks to the high molar absorptivity and the high intensity of the fluorescence emission of OTA, these techniques allow working at low concentration levels, which is desirable because of its high toxicity. Moreover, the reaction products under alkaline conditions were identified and the transformation products occurring when the solution is brought back to acidic conditions were studied. Under alkaline conditions, OTA displays degradation processes whose reaction products were revealed at $\mathrm{pH}$ above 12 , such as OTA with hydrolyzed lactone ring and ochratoxin alpha (OT $\alpha$ ) with hydrolyzed ring, obtained by hydrolysis of the amide bond of OTA. The product of lactone ring opening and OT $\alpha$ are less toxic than OTA. ${ }^{29}$ The reaction reversibility upon reacidification was ascertained by fluorescence spectroscopy.

The experimental findings were flanked by a Density Functional Theory (DFT) calculations, which were carried out for the first time to reveal the most probable reaction products of the degradation mechanism of OTA. The scope of this work was to provide detailed information about the protonation equilibria of OTA and to determine the conditions of irreversible toxicity deletion of the toxin due to $\mathrm{pH}$ and time effects. The analysis of UV-Vis and fluorescence spectra and the determination of $\mathrm{p} K_{\mathrm{a}}$ values were meant to augment and improve the related literature. Moreover, DFT was needed to identify the thermodynamically stable reaction products responsible of the experimental bands obtained in the fluorescence maps. Novel results required for further OTA investigations were provided by theoretical degradation path calculation. The conditions upon which the different forms of OTA are stably present in aqueous solution would allow to obtain aqueous solutions containing mainly one specific form of OTA. This paves the way towards specific toxicological studies of OTA in different protonation and hydrolyzation conditions.

The full identification of the reaction products of OTA throughout a wide $\mathrm{pH}$ range was needed to elucidate the chemical behaviour, which influences the toxicological profile of each OTA form and has strong biological implications..$^{27,29-32}$ A comprehensive description of OTA behaviour in aqueous solutions in the $\mathrm{pH}$ range $1.0-12.5$ was carried out to provide useful information for further toxicological studies of one of the most dangerous and diffused natural foodstuff toxins.

\section{Experimental section}

\subsection{Chemicals}

A reference material composed of a solution of OTA $\left(1 \mathrm{~g} \mathrm{~L}^{-1}\right.$ in dimethyl sulfoxide, Sigma-Aldrich) was used to prepare the solutions for the spectrophotometric measurements. Diluted stock solutions at $0.001 \mathrm{~g} \mathrm{~L}^{-1}$ were used for the fluorescence spectroscopy. All OTA solutions were prepared in ultra-pure water (Milli-Q quality).

The ionic strength was fixed at $0.4 \mathrm{~mol} \mathrm{~L}^{-1}$ with phosphate buffer, for OTA solutions under neutral conditions, and at $0.1 \mathrm{~mol} \mathrm{~L}^{-1}$ with $\mathrm{KCl}$ for OTA solutions under acidic and alkaline conditions. Aliquots of $\mathrm{HCl}\left(0.1 \mathrm{~mol} \mathrm{~L}^{-1}\right)$ and $\mathrm{NaOH}$ (0.01 $\mathrm{mol} \mathrm{L}^{-1}$ or $0.5 \mathrm{~mol} \mathrm{~L}^{-1}$, concentration standardised against potassium hydrogen phthalate) were used to adjust the $\mathrm{pH}$.

The UV-vis spectrophotometric measurements were conducted on OTA solutions $2 \times 10^{-5} \mathrm{~mol} \mathrm{~L}^{-1}$. For fluorescence spectroscopy, the concentration of OTA was $1.24 \times$ $10^{-7} \mathrm{~mol} \mathrm{~L}^{-1}$. Under neutral conditions, a phosphate buffer 
composed of $\mathrm{NaH}_{2} \mathrm{PO}_{4}\left(0.1 \mathrm{~mol} \mathrm{~L}{ }^{-1}\right) / \mathrm{Na}_{2} \mathrm{HPO}_{4}\left(0.1 \mathrm{~mol} \mathrm{~L}{ }^{-1}\right)$, was added to OTA solutions for their stabilization. $\mathrm{HCl} 37 \%$ was added to study the reversibility of OTA degradation from alkaline to acidic conditions. A standard OT $\alpha$ solution (10.2 \pm $0.1 \mathrm{mg} \mathrm{L}^{-1}$ in acetonitrile, LGC Standards) was used for fluorescence spectroscopy analysis.

Reagents were at high purity level. NaClO (5\% active chlorine) was used to clean the glassware. OTA solutions were stored at $4{ }^{\circ} \mathrm{C}$ in the dark.

\subsection{Methods}

2.2.1 Spectrophotometric measurements and stoichiometric analysis. The absorption spectra of OTA solutions were acquired in the range $250-450 \mathrm{~nm}$ with a Jasco V-550 UV-Vis double-beam spectrophotometer, provided with Hellma quartz cuvettes for flow-through measurement $(10.00 \mathrm{~mm}$ optical path length). The $\mathrm{pH}$ of the solutions was evaluated by a Metrohm potentiometer (model 713, resolution of $0.001 \mathrm{pH}$ units) equipped with a Metrohm combined glass electrode (mod. 6.0259.100). The combined electrode was daily calibrated in terms of $\mathrm{H}^{+}$concentration. The slope and the formal potential $E^{0}$ of the Nernst equation were elaborated by the ESAB2M program..$^{33}$ The experiments were conducted in oxygen-free atmosphere by flowing nitrogen in the solution, in continuous stirring, at $25{ }^{\circ} \mathrm{C}$ (thermocryostat mod. D1-G Haake). Initially, the OTA solution $(20 \mathrm{~mL})$ was adjusted to $\mathrm{pH} 3$ with $\mathrm{HCl}$. Subsequent aliquots of $\mathrm{NaOH}$ solution $(10 \mu \mathrm{L})$ were added by a Metrohm 765 Dosimat burette (resolution $1 \mu \mathrm{L}$ ) until the OTA solution reached a $\mathrm{pH}$ value of about 7.5. Each addition corresponded to an increase of $0.1 / 0.2 \mathrm{pH}$ units.

A total of 45 UV-Vis spectra were elaborated with HypSpec ${ }^{\circledR}$ software $^{34}$ that operates with stoichiometric principles by applying mass and charge balance equations and LambertBeer's law.

2.2.2 Fluorescence spectroscopy and chemometric analysis. Excitation-emission maps (EEMs) of OTA solutions at different $\mathrm{pH}$ were collected. A Horiba Scientific Fluorolog-3 spectrofluorometer (model FL3-21) provided with a Hellma quartz cuvette (10.00 mm optical pathlength) was used. OTA solutions were measured in right angle geometry. ${ }^{35}$ The excitation and emission range of 310-395 $\mathrm{nm}$ and 400-475 $\mathrm{nm}$, respectively (wavelength resolution $1 \mathrm{~nm}$ ). $2 \mathrm{~nm}$ slits and integration time of $1 \mathrm{~s}$ were used for the EEMs related both to the determination of $\mathrm{p} K_{\mathrm{a}}$ values and for the degradation steps investigation. For the determination of the $\mathrm{p} K_{\mathrm{a} 1}$ EEMs were elaborate by Parallel Factor Analysis (PARAFAC) ${ }^{36-39}$ using PLS Toolbox from Eigenvector Research, Inc. for Matlab R2015a (Mathworks). The size of the EEMs array was $12 \times 86 \times 76$, where 12 are the samples, 86 the number of emission wavelengths and 76 the number of excitation wavelengths in the scanned ranges. Multiway center was applied as data preprocessing and non negativity and unimodality constraints were use. The scores of the two involved components (neutral and monoanionic) were plotted as a function of $\mathrm{pH}$ and fitted with a linear and a 2 nd order polynomial function. Then, the intersection of the two curves was calculated. The fits' uncertainty was calculated and propagated by Monte
Carlo method. ${ }^{40}$ For the determination of $\mathrm{p} K_{\mathrm{a} 2}$, PARAFAC modeling was not adopted since the excitation bands were sufficiently distincted in the EEM. The bands' intensity of the two species (monoanionic and dianionic) was evaluated at fixed $\lambda_{\mathrm{Em}}$ $446 \mathrm{~nm}$. The intensity ratio $I_{332}$ over $I_{372}$ was used to estimate the $\mathrm{p} K_{\mathrm{a} 2}$. The experimental ratio points plotted against the $\mathrm{pH}$ were fitted using an exponential decay function and the uncertainty related to the fit was evaluated. $\mathrm{p} K_{\mathrm{a} 2}$ corresponds to $I_{332} / I_{372}=1$, with its associated uncertainty deriving from the fit.

To elucidate the degradation process, the EEMs with the bands related to the significant reaction products were identified. Moreover, the EEM of the final reaction products in the degradation process was compared with the EEM obtained by the analysis of the standard OT $\alpha$ solution as a confirmation.

\subsection{Theoretical method}

All stationary points on the energy hypersurface were determined by gradient procedures ${ }^{41-45}$ within DFT. ${ }^{46}$ The $\omega$ B97XD functional was chosen..$^{47}$ Pople's $6-311++G(d, p)$ basis set ${ }^{48,49}$ was used in the DFT optimizations and in the vibrational analysis (both including solvent effects), by which the nature of the critical points was checked. The reacting molecules were considered as a solute in a polarized continuum (water), within the Solvation Model based on Density (SMD) ${ }^{50,51}$ and Integral Equation Formalism-Polarizable Continuum Model (IEF-PCM) schemes. ${ }^{52}$ One explicit water molecule was considered only for the steps TI1-4 and TI2-5 (TI = tetrahedral intermediate), because literature data ${ }^{53-55}$ show that water helps the bond cleavage by cooperating in a hydrogen transfer. These two barriers, without the cooperative effect of explicit water, are significantly overestimated.

Throughout the paper, the relative Gibbs free energies in solution $(\Delta G)$ are reported, estimated at $T=298 \mathrm{~K}$, and expressed in $\mathrm{kcal} \mathrm{mol}^{-1}$.

Excitation energies were calculated by single point time dependent-DFT calculations, ${ }^{56-59}$ using the O3LYP functional ${ }^{60}$ and the same basis set of the optimizations. Other functionals were also tested and O3LYP was found to better reproduce the experimental spectrum of the OTA. It was also satisfactorily used in some recent works. ${ }^{\mathbf{6 1 , 6 2}}$ The first 6 excited states were calculated for each structure. Simulated UV absorption spectra were obtained by using Gaussian convolution with half width value $\sigma=0.4$, as described in http://gaussian.com/uvvisplot/.

Geometry optimizations and thermochemistry calculations were carried out by using the Gaussian 09 system of programs. ${ }^{63}$ The MOLDEN program ${ }^{64}$ was exploited to display the optimized transition structures reported in the ESI (Fig. S7 and S8†)

\section{Results and discussion}

\subsection{Proton dissociation}

The UV-Vis spectra recorded as a function of $\mathrm{pH}$ are reported in Fig. 2.

The spectra show defined isosbestic points at 346 and $297 \mathrm{~nm}$, suggesting the presence of two OTA forms, without intermediates in between. The absorption band at about 


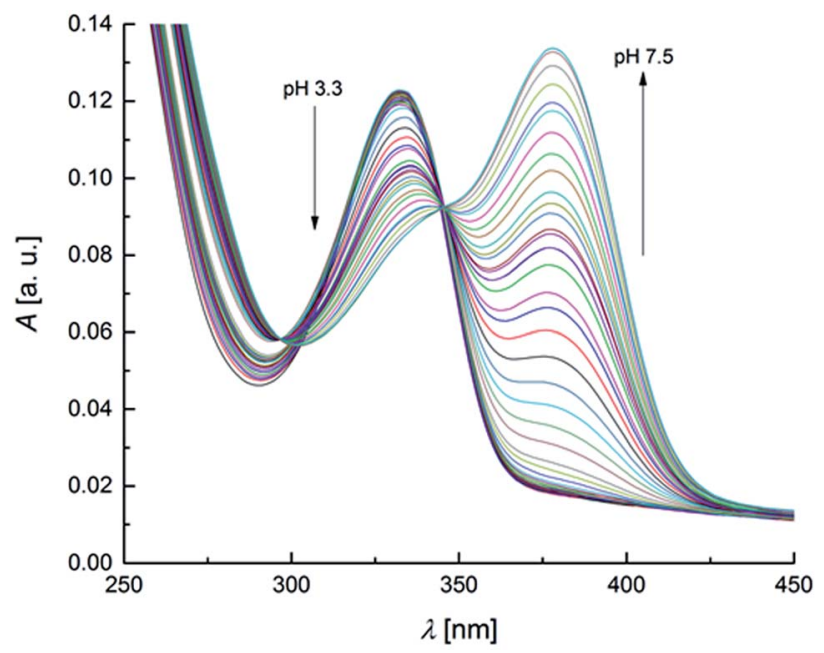

Fig. 2 UV-Vis spectra of OTA solution $\left(2 \times 10^{-5} \mathrm{~mol} \mathrm{~L}^{-1}\right)$ within the $\mathrm{pH}$ range $3.3-7.5$ (increment of $0.1-0.2 \mathrm{pH}$ units for each spectrum).

$332 \mathrm{~nm}$ could be attributed to both neutral and monoanionic forms (1 in Scheme 1) because they absorb at the same wavelength. The absorption band at $378 \mathrm{~nm}$ was associated to the dianionic form (3 in Scheme 1). These results are in accordance with the absorption spectra reported in literature..$^{32,65}$ The values of the molar absorptivity $(\varepsilon)$ for the three OTA forms, $\mathrm{p} K_{\mathrm{a} 1}$ and $\mathrm{p} K_{\mathrm{a} 2}$ were deduced by the HypSpec ${ }^{\circledR}$ software. Fig. S1 in the ESI $\dagger$ shows the variation of $\varepsilon$ as a function of $\lambda$ for each OTA form.

In Table 2, the experimental and calculated values of maximum absorptivity, $\varepsilon_{\max }$, and maximum absorption wavelength, $\lambda_{\max }$, obtained by the theoretical method and spectrophotometric measurements are compared with literature data (the simulated UV spectra are reported in Fig. S2 $\dagger$ ). A good agreement between experimental, calculated and literature values was found. No data concerning the $\varepsilon_{\max }$ of the monoanionic form of OTA were found in literature.

Even though the absorption bands related to the neutral and monoanionic forms are strongly overlaid, the elaboration of UVVis data with HypSpec ${ }^{\circledR}$ not only allows to define a value for $\mathrm{p} K_{\mathrm{a} 2}$ but also an estimate of $\mathrm{p} K_{\mathrm{a} 1}$. The details of the calculation procedure are reported in the ESI file. $\uparrow$ The values of the protonation constants, and the corresponding standard deviations, were evaluated: $\mathrm{p} K_{\mathrm{a} 1}=4.4 \pm 0.1$ and $\mathrm{p} K_{\mathrm{a} 2}=7.09 \pm 0.01$. These results are in quite good agreement with the literature data. ${ }^{24-30}$

Concerning the fluorescence spectroscopy measurements, a set of 12 EEMs of OTA solutions under acidic and neutral conditions was acquired in the $\mathrm{pH}$ range 1.0-6.0, where two known fluorophores (neutral and monoanionic OTA) are present in different ratios. The total fluorescence spectra obtained between $\mathrm{pH}$ 1.0-4.8 show a single band at excitation/ emission wavelengths $\left(\lambda_{\mathrm{Ex} / \mathrm{Em}}\right)$ of $332 / 458 \mathrm{~nm}$ (Fig. 3a), which gradually shifts to $\lambda_{\mathrm{Ex} / \mathrm{Em}}=328 / 446 \mathrm{~nm}$ increasing the $\mathrm{pH}$ (Fig. 3b). This shift is due to the transition from the neutral form of OTA to the monoanionic form (1). The dianionic form (3) is still absent in this $\mathrm{pH}$ range.
Since the neutral form and 1 exhibit two overlapping bands, PARAFAC was used to mathematically separate the contributions and obtain a concentration profile of the two forms along the $\mathrm{pH}$ scale. The two components PARAFAC model explains $61.1 \%$ of variance and shows $100 \%$ of core consistency. The PARAFAC emission and excitation loadings can be considered as the best approximations of the fluorescence spectra of pure analytes. The obtained emission profiles of neutral form and 1 were in agreement with raw emission spectra obtained at fixed $\lambda_{\text {Ex }}$ of $332 \mathrm{~nm}$, that show emission maxima at $458 \mathrm{~nm}$ and $446 \mathrm{~nm}$ (Fig. 4a). Fig. S3† shows the loadings profile corresponding to the emission mode. The intensity maxima of the modeled emission spectra (i.e. the loadings) are positioned at $\lambda_{\mathrm{Em}}$ of $459 \mathrm{~nm}$ and $436 \mathrm{~nm}$. The first component is associated to neutral OTA, present at $\mathrm{pH}<4$, whereas the second component is associated to $\mathbf{1}$, that appears at $\mathrm{pH} \simeq 3$ and becomes predominant at $\mathrm{pH}>4$. The modeled excitation profiles of the two forms are superimposed with $\lambda_{\mathrm{Ex}}=332 \mathrm{~nm}$, in agreement with the absorption spectra of Fig. S1. $\dagger$ However, the slight differences in the $\lambda_{\mathrm{Em}}$ were sufficient to estimate them separately. The scores of the model represent the amount of each form at each $\mathrm{pH}$ value (Fig. 4b). The point where the concentration curve of 1 intersects that of the neutral form corresponds to the $\mathrm{p} K_{\mathrm{a} 1}$. The $\mathrm{p} K_{\mathrm{a} 1}$ value obtained with this model was estimated 4.2 with a fit uncertainty of 0.9 .

7 EEMs between $\mathrm{pH} 4.8-8.3$ were acquired to investigate the $\mathrm{p} K_{\mathrm{a} 2}$ range where monoanionic form (1) and dianionic form (3) intervene. As long as the $\mathrm{pH}$ increases, a decrease of $\mathbf{1}$ is evidenced in Fig. $3 \mathrm{c}$ and $\mathrm{d}$ and a new peak rises at $\lambda_{\mathrm{Ex} / \mathrm{Em}}=372 /$ $443 \mathrm{~nm}$, due to 3.1 and 3 showed two separated maxima in correspondence of $\lambda_{\mathrm{Em}}=446 \mathrm{~nm}$. The normalised and fitted excitation spectra are reported in Fig. 5a. The excitation spectrum at $\lambda_{\mathrm{Em}}=446 \mathrm{~nm}$ was isolated to evaluate the excitation maxima of the two forms of OTA at $\lambda_{\mathrm{Ex}}=332 \mathrm{~nm}(\mathbf{1})$ and $\lambda_{\mathrm{Ex}}=$ $372 \mathrm{~nm}$ (3) (Fig. 5a). The intensity $I_{332}$ to $I_{372}$ ratio between 1 and 3 was used to estimate the value of $\mathrm{p} K_{\mathrm{a} 2}$, which is the $\mathrm{pH}$ value corresponding to the inversion of the intensity ratio (Fig. $5 \mathrm{~b}$ ). The $\mathrm{p} K_{\mathrm{a} 2}=7.15$ was estimated. However, this value was obtained at an ionic strength $0.4 \mathrm{~mol} \mathrm{~L}^{-1}$. In order to make this $\mathrm{p} K_{\mathrm{a} 2}$ value comparable with the value obtained by UV-Vis spectrophotometry and with literature data, it was adjusted considering the ionic strength $0.1 \mathrm{~mol} \mathrm{~L}^{-1}$. Upon application of an extended Debye-Hückel equation, ${ }^{66}$ the $\mathrm{p} K_{\mathrm{a} 2}$ was evaluated 7.0 with a fit uncertainty of 0.4 .

It can be noticed that the maximum attributed to 1 undergoes a shift toward higher $\lambda_{\mathrm{Ex}}$ going from pH 6.6 (Fig. 3c) to $\mathrm{pH} 7.1$ (Fig. 3d). This effect can be ascribed to the swelling of the band attributed to 3, while a significant overlap of the two bands is present. Deconvolution of the profile along $\lambda_{\mathrm{Ex}}$ clearly shows the origin of the maximum shift (Fig. S4†).

Fig. 6 shows the distribution diagram of the differently protonated forms of OTA, as a function of $\mathrm{pH}$, starting by the $\mathrm{p} K_{\mathrm{a} 1,2}$ values obtained by both spectrophotometric and fluorescence data. The spectrophotometric and fluorescence $\mathrm{p} K_{\mathrm{a} 1}$ (namely 4.4 and 4.2) and $\mathrm{p} K_{\mathrm{a} 2}$ (namely 7.09 and 7.0) represent consistent results. 
<smiles>C[IH]Oc1c(C(=O)NC(Cc2ccccc2)C(=O)[O-])cc(Cl)c2c1C(=O)O[C@@H](C)C2</smiles>

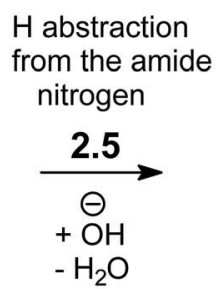<smiles>CC(Cc1ccccc1)C(=O)[O-]</smiles>

$1 \quad 0.0 \quad \lambda=333 \mathrm{~nm}$

$2 \quad \mathbf{- 5 . 2} \lambda=303 \mathrm{~nm}$

(C-C rotation and $\mathrm{H}^{+}$

transfer)

\section{7/3.0}

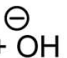

$-\mathrm{H}_{2} \mathrm{O}$

7.7 $\mathrm{H}$ abstraction from the phenol

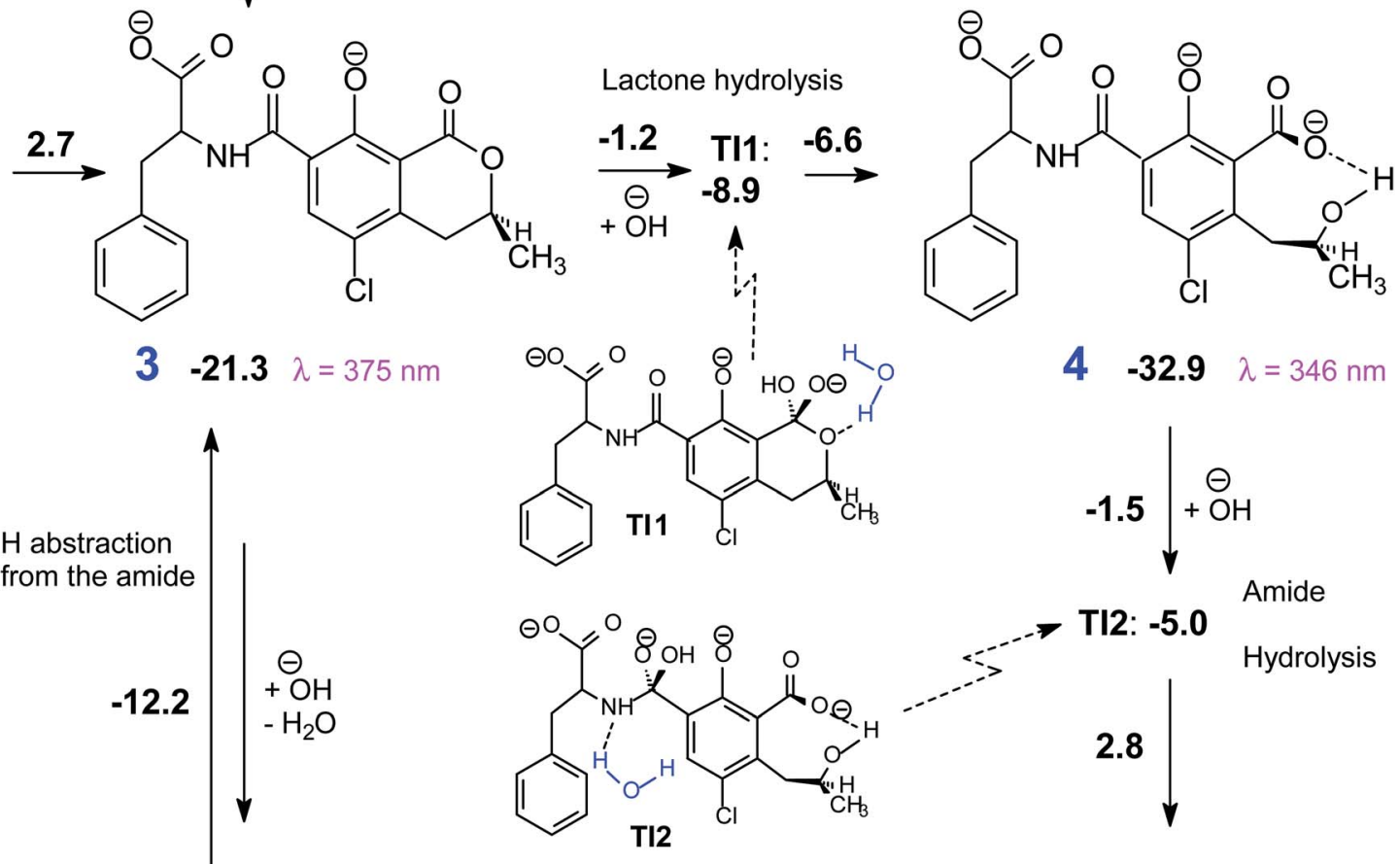<smiles>C[C@H]1Cc2c(Cl)cc(C(=O)N[C@@H](Cc3ccccc3)C(=O)O)c([O-])c2C(=O)O[C@@H]1C(=O)O</smiles><smiles></smiles>

$5 a$

$\lambda=239 \mathrm{~nm}$
$5 b$

$\lambda=331 \mathrm{~nm}$

Scheme 1 The most viable reaction pathways that connect 1 to the degradation products (5). Gibbs free energy differences with respect to 1 in $\mathrm{kcal} \mathrm{mol}^{-1}$.

The mechanism proposed theoretically is sketched in Scheme 1. The related Gibbs free energy profiles are shown in Fig. 7. The reaction pathway, starting from the monoanionic form of OTA
(1), branches right from the beginning upon $\mathrm{HO}$ attack onto 1 . If $\mathrm{HO}^{-}$abstracts a proton from $\mathrm{N}-\mathrm{H}\left(\Delta G^{\ddagger}=2.5 \mathrm{kcal} \mathrm{mol}^{-1}\right)$ the resonant amide anion 2 is generated. On the other hand, upon 
Table $2 \lambda_{\max }$ and $\varepsilon_{\max }$ (experimental and calculated) values for the different OTA forms

\begin{tabular}{|c|c|c|c|c|c|c|}
\hline Source & \multicolumn{2}{|c|}{ Neutral form } & \multicolumn{2}{|c|}{ Monoanionic form } & \multicolumn{2}{|c|}{ Dianionic form } \\
\hline Il'ichev et al. $(2001)^{32}$ & 332 & 6650 & 332 & - & 380 & 10970 \\
\hline Verrone et al. $(2007)^{65}$ & 330 & 6600 & 330 & - & 379 & 9115 \\
\hline
\end{tabular}

hydrogen abstraction from the phenolic $\mathrm{O}-\mathrm{H} \quad\left(\Delta G^{\ddagger}=\right.$ $7.7 \mathrm{kcal} \mathrm{mol}^{-1}$ ) the phenate $\mathbf{3}$ forms. Whilst the 1-2 step is kinetically favoured over $\mathbf{1 - 3}, \mathbf{2}$ is thermodynamically less stable than $\mathbf{3}$, and the backwards step 2-1 requires overcoming a barrier of $7.7 \mathrm{kcal} \mathrm{mol}^{-1}$. Alternatively, the anion 2 can undergo a clockwise or anti-clockwise rotation around the $\mathrm{C}-\mathrm{C}$ bond highlighted in red in Scheme 1. This movement defines two rotation transition structures and opens the way to two nonequivalent hydrogen migrations from the phenolic $\mathrm{O}$ to the partially anionic $\mathrm{N}$. Two series of constrained optimizations were carried out, in correspondence of frozen values of the dihedral angle that expresses the said rotation in opposite directions. In the highly asynchronous concerted $2-3$ processes, $\mathrm{C}-\mathrm{C}$ rotation entails barriers with $\Delta G^{\ddagger}=7.9$ or $8.2 \mathrm{kcal} \mathrm{mol}^{-1}$ height. Following either all-downhill pathway from each rotation
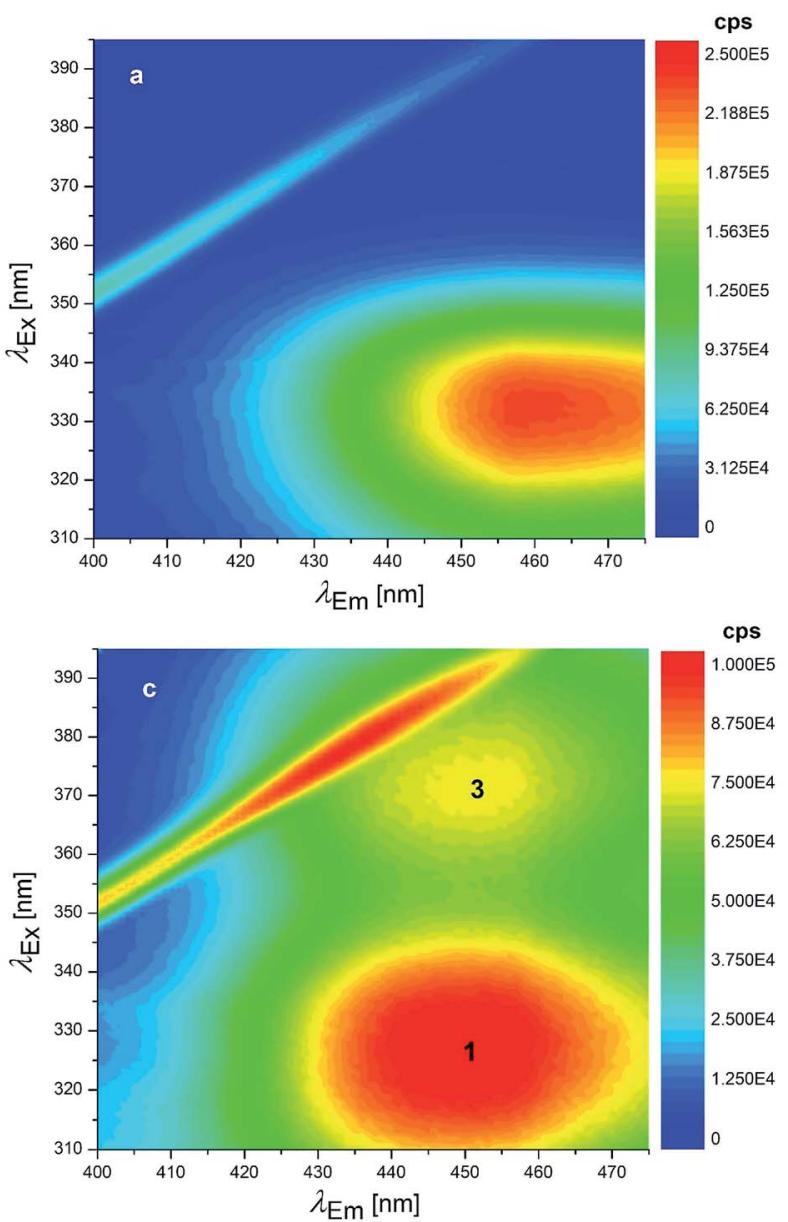

transition structure shows that the subsequent $\mathrm{H}$ transfer takes place in both cases without any barrier. The result is in both cases the phenate (dianionic form of OTA) 3 , which is consequently formed from 1 in two ways: directly (1-3), as expected, and also indirectly (1-2-3). The latter process is preferred because the second step is unimolecular. The excitation energy of 2 (computed peak at $303 \mathrm{~nm}$ ) may not be observed experimentally because 1 transforms to 3 rather easily. The calculated excitation energy of $3(375 \mathrm{~nm})$ is consistent with the $372 \mathrm{~nm}$ maximum in the spectrum displayed in Fig. $3 \mathrm{c}$ and d.

\subsection{Degradation processes}

Several degradation pathways are conceivable from 3 (Scheme S1†). The two most probable are reported in Scheme 1. In both of them an acyl group is hydrolyzed. The 3-4 lactone hydrolysis is a two-step
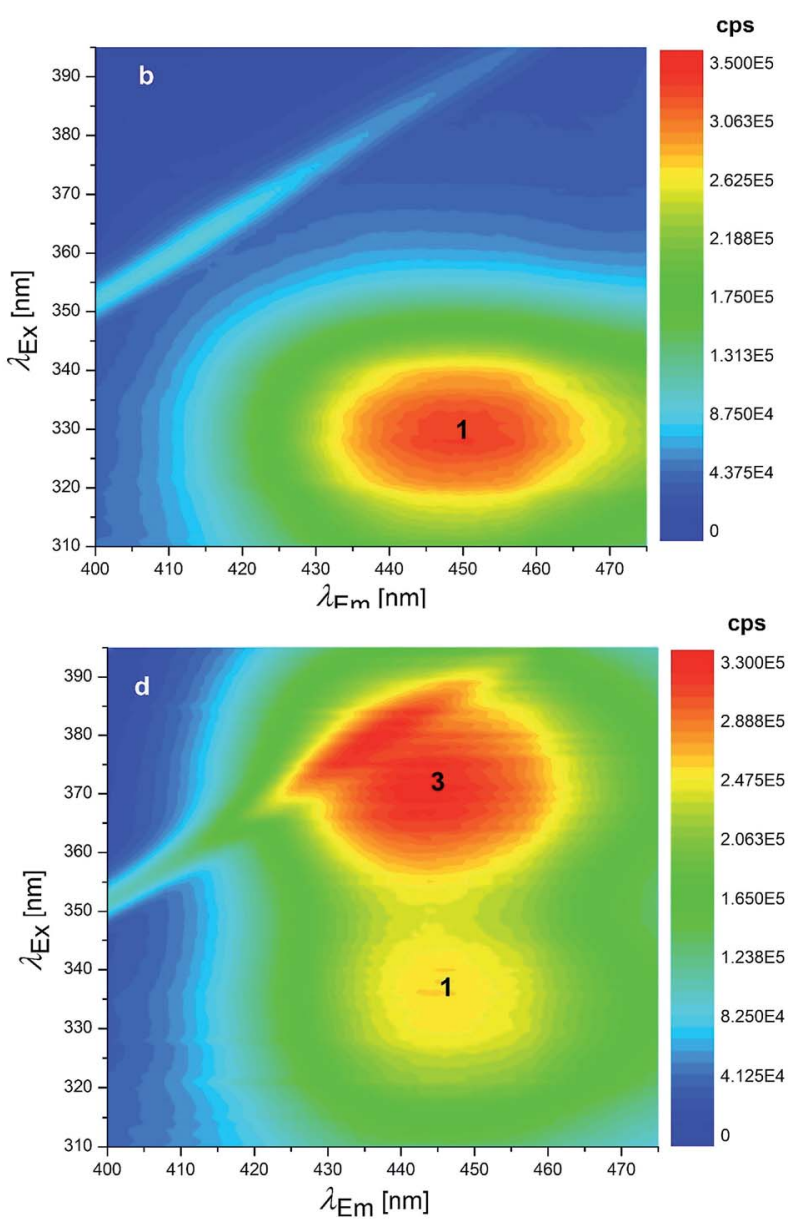

Fig. 3 EEMs of $1.24 \times 10^{-7}$ mol L ${ }^{-1}$ OTA solutions: (a) $\mathrm{pH} 1.0$ ( $\mathrm{HCl}$ solution), (b) 4.8 ( $\mathrm{HCl}$ solution), (c) 6.6 (phosphate buffer) and (d) 7.1 (phosphate buffer). The numbers superimposed on the bands of these EEMs make reference to the molecular structures reported in Scheme 1. 

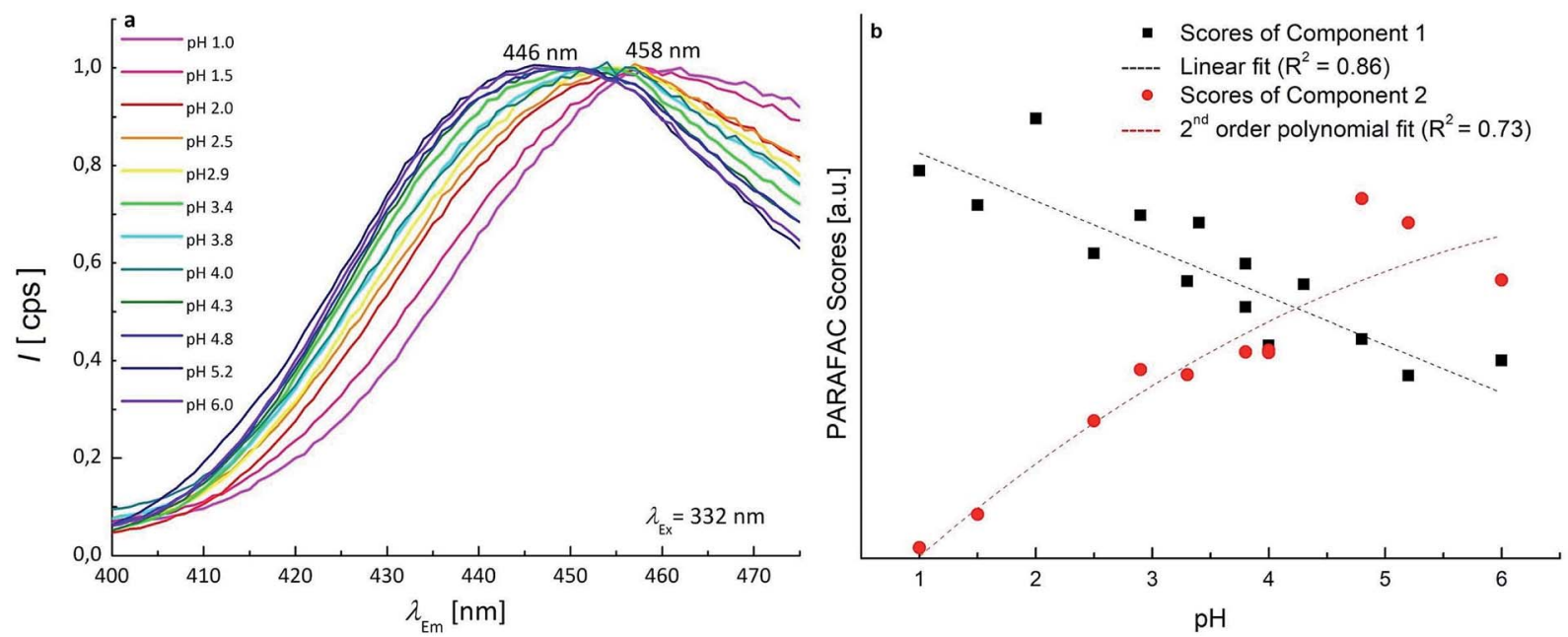

Fig. 4 (a) Experimental emission spectra of OTA $1.24 \times 10^{-7} \mathrm{~mol} \mathrm{~L}^{-1}$ in the $\mathrm{pH}$ range 1.0-6.0 (normalised intensity scale); (b) scatter scores plot as a function of $\mathrm{pH}$, the scores of the two components of PARAFAC model are shown.

reaction, which passes through the tetrahedral intermediate TI1 (12.4 kcal mol ${ }^{-1}$ higher in energy than 3). The slowest step is 3-TI1 $\left(\Delta G^{\ddagger}=20.1 \mathrm{kcal} \mathrm{mol}^{-1}\right)$, in good agreement with the barrier of $19.2 \mathrm{kcal} \mathrm{mol}^{-1}$ estimated by Gómez-Bombarelli et al. ${ }^{53}$ for the valerolactone (however their calculations including six explicit water molecules). Then, a fast ring opening leads to the trianion 4. The inclusion of one explicit molecule of water was necessary to obtain a more reliable estimate of its barrier $\left(\Delta G^{\ddagger}=2.3 \mathrm{kcal} \mathrm{mol}^{-1}\right)$. Otherwise, the barrier would have been $9.1 \mathrm{kcal} \mathrm{mol}^{-1}$ high. Water promotes hydrogen migration by taking one $\mathrm{H}$ and leaving another. Despite only one water molecule was added, the barrier is closer to that calculated by Gómez-Bombarelli et al. who found $\Delta G^{\ddagger}=$ $3.9 \mathrm{kcal} \mathrm{mol}^{-1}$. The overall energy barrier 3-4 is rather high, and consequently the reaction is supposed to be quite slow: this is the likely reason why the experimental signal at $346 \mathrm{~nm}$ (Fig. 8b) appears only after several days at $\mathrm{pH} 11.5$, or after about one hour at $\mathrm{pH} 12.5$ (the computed absorption is at $346 \mathrm{~nm}$ as well). Subsequently, $\mathbf{4}$ can undergo an alkaline hydrolysis of the amide group. It is again a two-step reaction through a tetrahedral intermediate TI2. The first step presents an energy barrier of $31.4 \mathrm{kcal} \mathrm{mol}^{-1}$.

In order to assess the importance of introducing explicit water molecules, two tests the first hydrolysis step of $\mathrm{N}$-methylacetamide were carried out. For this molecule experimental data are available. ${ }^{55}$ For the test, the $\omega \mathrm{B} 97 \mathrm{XD} / 6-31+\mathrm{G}(\mathrm{d})$ method was used, first without explicit water molecules and then including 8 explicit $\mathrm{H}_{2} \mathrm{O}$ molecules. In both cases the surrounding solvent was introduced as a polarizable continuum. Without explicit water, the free energy barrier for the $\mathrm{OH}$ addition, the first step of the hydrolysis, is $\Delta G^{\ddagger}=$ $25.4 \mathrm{kcal} \mathrm{mol}^{-1}\left(\Delta H^{*}=13.9 \mathrm{kcal} \mathrm{mol}^{-1}\right)$, with 8 water molecules drops to $\Delta G^{\ddagger}=19.2 \mathrm{kcal} \mathrm{mol}^{-1}\left(\Delta H^{\star}=16.7 \mathrm{kcal} \mathrm{mol}^{-1}\right)$. The experimental value is $\Delta G^{\ddagger}=22.9 \mathrm{kcal} \mathrm{mol} \mathrm{m}^{-1}\left(\Delta H^{\ddagger}=\right.$ $\left.17.1 \mathrm{kcal} \mathrm{mol}{ }^{-1}\right) \cdot{ }^{55}$ The addition of explicit solvent molecules clearly has lowered the barrier, but still with unsatisfactory agreement when free energy differences are considered. In any case, inclusion of a large number of explicit solvent molecules
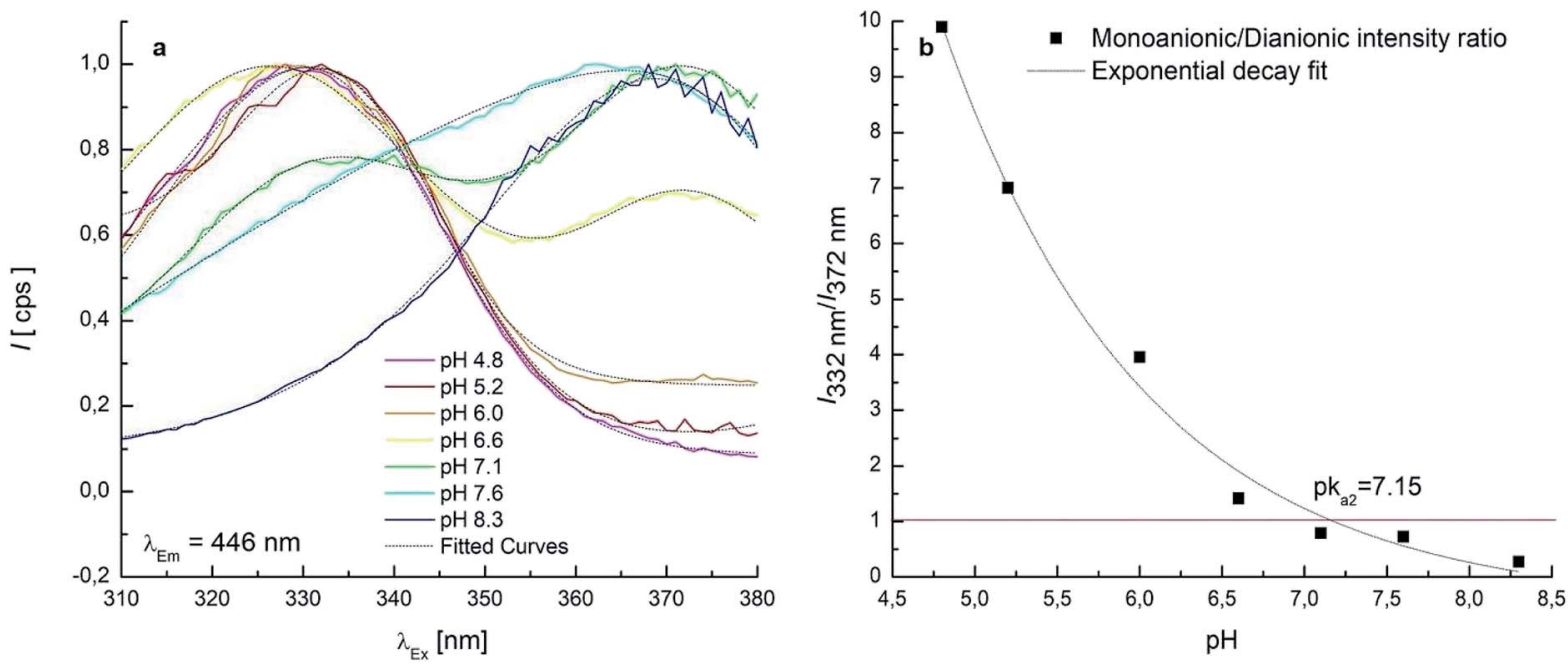

Fig. 5 (a) Excitation spectra collected at fixed $\lambda_{\mathrm{Em}}=446 \mathrm{~nm}$ in the $\mathrm{pH}$ range $4.8-8.3$ (normalised intensity scale and Gaussian fitted curves); (b) monoanionic/dianionic intensity $/ 332$ to $/ 372$ ratio as a function of the solution $\mathrm{pH}$. 


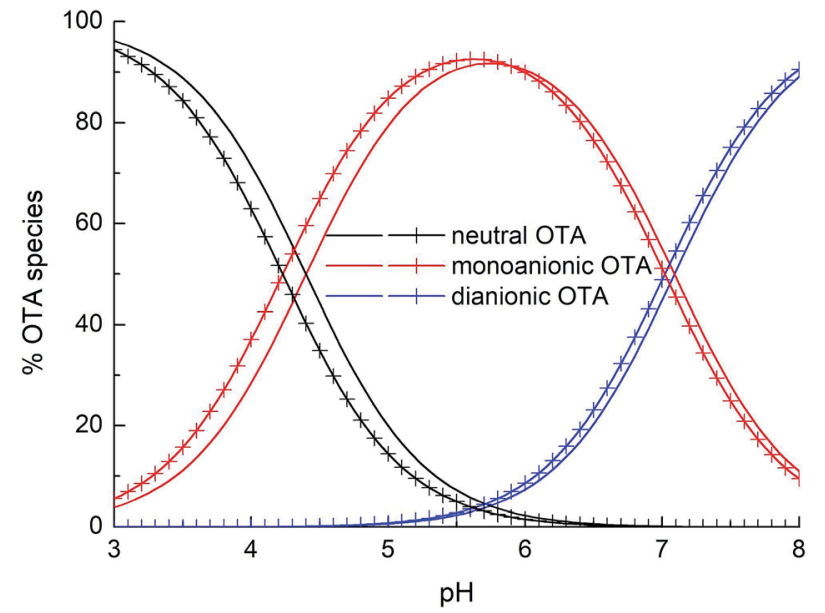

Fig. 6 Percentage distribution of the OTA forms as a function of $\mathrm{pH}$ for a solution $2 \times 10^{-5} \mathrm{~mol} \mathrm{~L}^{-1}$. Solid lines: species distribution obtained from UV-Vis spectra elaboration; lines with crosses: species distribution obtained from fluorescence data elaboration.

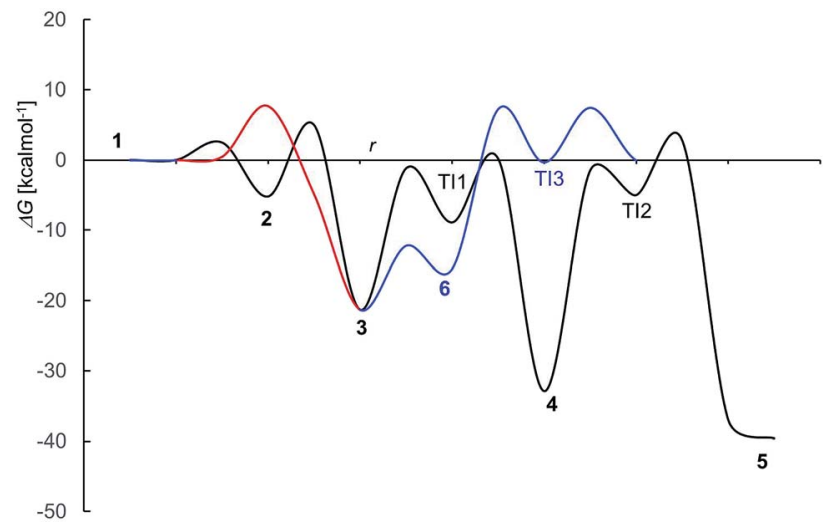

Fig. 7 Free energy profile for OTA alkaline deprotonation and degradation (compare Scheme 1); $r$ stays for a generic "reaction coordinate".

would be unfeasible on the OTA molecule. The initial and transition structures are displayed in Fig. S8 of the ESI. $\dagger$

The barrier for the cleavage of TI2, is overestimated if no explicit water molecules are introduced (see Tang et al. $;^{54} \mathrm{Gal}-$ abov et al. ${ }^{55}$ ). One $\mathrm{H}_{2} \mathrm{O}$ molecule added in the calculation lowered the barrier to $7.8 \mathrm{kcal} \mathrm{mol}^{-1}$, from $17.6 \mathrm{kcal} \mathrm{mol}^{-1}$ estimated without the said cooperative effect. Regarding the amide hydrolysis $\mathbf{4 - 5}$, the overall§ barrier is huge: $35.7 \mathrm{kcal} \mathrm{mol}^{-1}$. It can be surmised that the present estimate of the barrier is too high, due to the approximate description of water solvation. Anyhow, it indicates an extremely slow

\footnotetext{
¥ The TS TI2-5 actually leads to a somewhat stable intermediate, in which a water proton has moved to nitrogen, leaving an $\mathrm{OH}^{-}$interacting with a quaternary cation, shown in Fig. S9. Its potential energy is below the TS, but its free energy lies $0.2 \mathrm{kcal} \mathrm{mol}^{-1}$ above it. This intermediate easily dissociates to $\mathbf{5 a}+\mathbf{5 b}\left(\Delta G^{\ddagger}\right.$ $=1.0 \mathrm{kcal} \mathrm{mol}^{-1}$ ).

$\S$ For these two-step hydrolyses, we intend by 'overall barrier' the free energy difference between the highest-G transition structure TI1-4 or TI2-5 and the intermediates 3 or $\mathbf{4}$, respectively. In the first case $-1.2+21.3$, in the second 2.8 +32 (see Fig. 7).
}

reaction, consistently with the fluorescence results (detailed below) where one excitation peak around $313 \mathrm{~nm}$ (likely due to the OT $\alpha$ derivative $\mathbf{5 b}$ ) appears only after several days at $\mathrm{pH} 12.5$ (Fig. 8c). The computed value for the absorption peak of $\mathbf{5 b}$ is $331 \mathrm{~nm}$.

An alternative step from 3 begins with hydrogen abstraction from nitrogen to form the trianionic intermediate 6 (blue line in Fig. 7). This 3-6 step $\left(\Delta G^{*}=9.1 \mathrm{kcal} \mathrm{mol}^{-1}\right)$ is actually easier than 3-4. However, 6 is thermodynamically less stable than 3 : between 3 and 6 an equilibrium is established but strongly shifted towards 3. Moreover, the only reaction that might generate 6 is the lactone hydrolysis, whose first step leads to TI3 $\left(-0.3 \mathrm{kcal} \mathrm{mol}^{-1}\right.$ with respect to 1$)$; but an overall barrier of $23.0 \mathrm{kcal} \mathrm{mol}^{-1}$ hampers this hydrolysis. Lactone hydrolysis from 3 has a lower barrier $\left(21.5 \mathrm{kcal} \mathrm{mol}^{-1}\right)$ and leads to the trianionic amide $\mathbf{4}$, which is more stable than $\mathbf{3}$. Consequently, the well corresponding to 4 (Fig. 7) gets more easily populated than the well corresponding to 6 . Then the reaction can proceed from 4. Scheme 1 shows the intrinsic inclination of the OTA system to evolve towards OT $\alpha$, but the rate of the processes and the possible equilibria depends on $\mathrm{OH}^{-}$concentration.

The EEM of a fresh solution at pH 11.6, in Fig. 8a, shows a band positioned at $365 / 443 \mathrm{~nm}$ related to 3 . Fig. 8 b shows that at $\mathrm{pH}$ of 12.5 the fresh OTA solution degraded faster than the time of measurement. The new band at $\lambda_{\mathrm{Ex} / \mathrm{Em}} 346 / 440 \mathrm{~nm}$ was associated to OTA with the hydrolyzed lactone (4 in Scheme 1) because the excitation wavelength agrees with the theoretical $\lambda_{\max }=346 \mathrm{~nm}$ and with $\lambda_{\max }$ at $345 \mathrm{~nm}$ reported by Xiao et al. ${ }^{26}$ Conversely, it does not agree with $\lambda_{\max }$ at $385 \mathrm{~nm}$ at $\mathrm{pH} \geq 11$ reported by Bazin et al. ${ }^{67}$ Fig. $8 \mathrm{c}$ reports the EEM of the OTA solution at pH of 12.5 after 7 days. 4 is still present, but another peak arises at $\lambda_{\mathrm{Ex} / \mathrm{Em}}$ of $313 / 430 \mathrm{~nm}$, probably related to OT $\alpha$ with the hydrolyzed ring (5b in Scheme 1). However, if the solution is maintained at $\mathrm{pH}$ 11.5, $\mathbf{4}$ is still present after 9 days, and $\mathbf{5 b}$ probably does not form. The EEM of Fig. 8d shows the band of the standard solution of OT $\alpha$ adjusted at $\mathrm{pH}$ of 12.5 , and confirms the assignment of the band (see also Fig. $55 \dagger$ ). $\mathbf{5 b}$ derives from the amide hydrolysis under alkaline condition of $\mathbf{4}$ and is less toxic than OTA. The other reaction product is phenylalanine (5a in Scheme 1 ), whose band is at $258 / 284 \mathrm{~nm}$, outside the scanned range. ${ }^{68}$

In this work, studies of reversibility of the reaction products of OTA were also conducted. The OTA solution at pH 7.1, containing mainly 3 (Fig. 3d) was acidified down to $\mathrm{pH} 1.0$ using $\mathrm{HCl}$ solution. The correspondent EEM, measured as soon as the solution was acidified, shows a single band positioned at $\lambda_{\mathrm{Ex} / \mathrm{Em}}$ of $332 / 458 \mathrm{~nm}$ due to neutral form of OTA.

Regarding the reaction of OTA degradation under alkaline conditions, instead, the reversibility depends on what form is

I The computed value is significantly dependent of the dihedral angle related to the almost free rotation of the leftmost (in 5b) carboxylate group, not engaged in a hydrogen bond. The values span the rather large range $300-331 \mathrm{~nm}$, and the dihedral angle itself may be influenced by the interaction with explicit water molecules. 

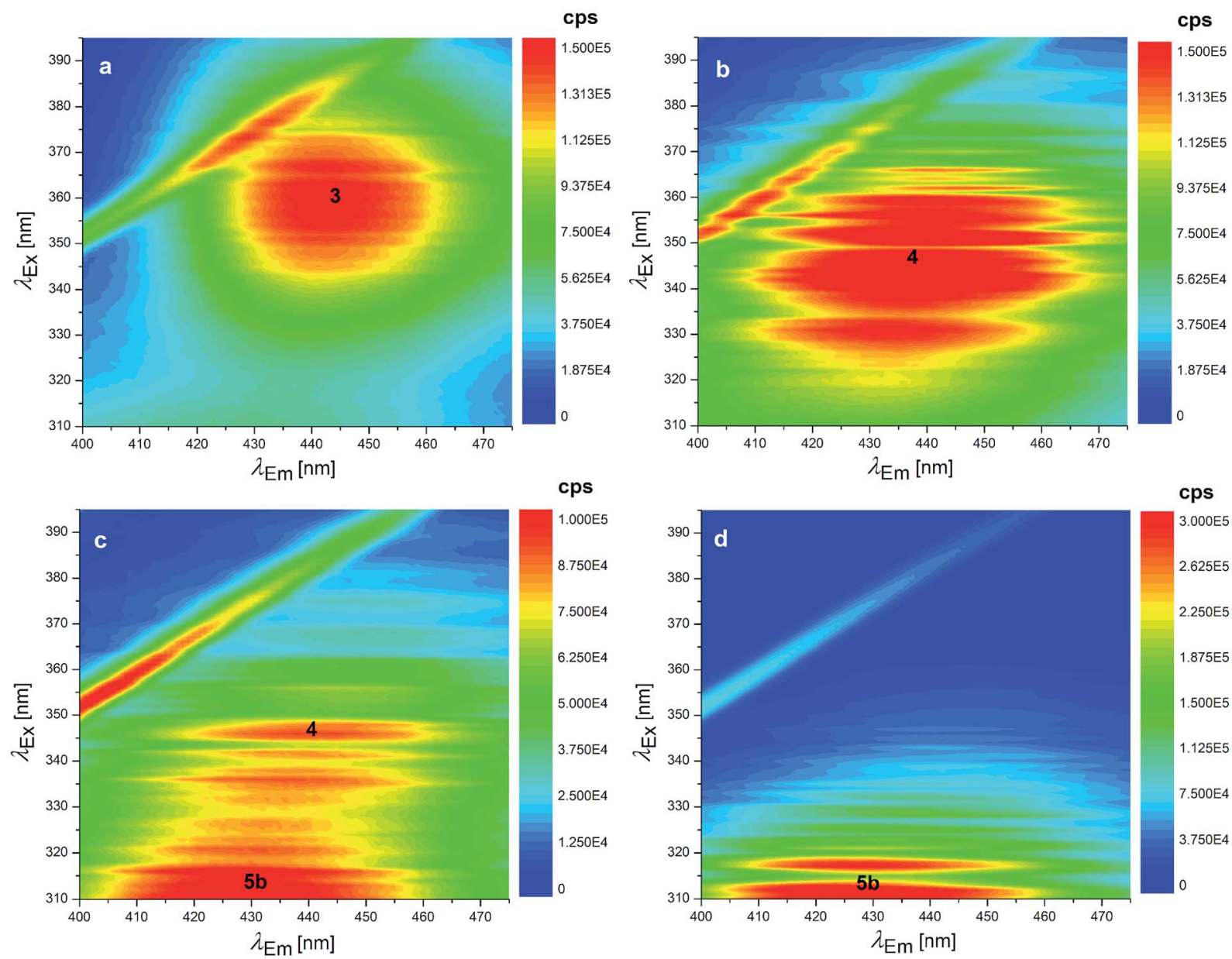

Fig. 8 EEMs of $1.24 \times 10^{-7} \mathrm{~mol} \mathrm{~L}^{-1}$ OTA solutions at pH: (a) 11.6 (fresh solution), (b) 12.5 (fresh solution), (c) 12.5 (as in b after 7 days stored at $4{ }^{\circ} \mathrm{C}$ in the dark) and EEM of $1.24 \times 10^{-7} \mathrm{~mol} \mathrm{~L}^{-1} \mathrm{OT} \alpha$ solution at $\mathrm{pH}$ : (d) 12.5 . The numbers superimposed on the bands of these EEMs make reference to the molecular structures reported in Scheme 1.

present in the solution. Indeed, while 4 is easily brought back to the neutral form of OTA by acidifying the solution, $\mathbf{5} \mathbf{b}$ does not return to the neutral form but returns to OT $\alpha$ (see Fig. S6 $\dagger$ ), as expected (5b does not reasonably react with $\mathbf{5 a}$ to form OTA again). Otherwise, at pH 12.5 after more than one month $\mathbf{5 b}$ does not return to OT $\alpha$.

In the computations, OT $\alpha$ was chosen as a proxy model for 4 to examine a possible backwards evolution of this intermediate. Re-acidification of a solution where $\mathbf{4}$ is predominant leads to the neutral form of OTA. In order to understand whether lactone regeneration is possible in acid environment, the acid-catalyzed backwards mechanism was considered, starting from the monoprotonated $\mathbf{5 b}$. The reaction seems to proceed very fast with low energy barriers toward a supposedly protonated OT $\alpha$ (Scheme 2). The free energy barrier for $\mathrm{H}_{2} \mathrm{O}$ loss from the protonated carboxylate group $\mathbf{A}$ is only $2.6 \mathrm{kcal} \mathrm{mol}^{-1}$. The acyl cation group in $\mathbf{B}$ can undergo intramolecular nucleophilic attack by the alcoholic hydroxyl $\left(\Delta G^{\ddagger}=0.6 \mathrm{kcal} \mathrm{mol}^{-1}\right)$ to form the very stable protonated lactone $\mathbf{C}$.<smiles>CC(O)Cc1c(Cl)cc(C(=O)O)c(O)c1C(=O)[OH2+]</smiles>

A $\quad 0.0$<smiles>CC(O)Cc1c(Cl)cc(C(=O)O)c(O)c1C(=O)O</smiles>

B<smiles>C[C@H]1Cc2c(Cl)cc(C(=O)O)c(O)c2C(=O)O1</smiles>

C $\quad-16.3$

Scheme 2 Acid-catalysed lactone formation. 


\section{Conclusions}

The proton dissociations and the degradation processes of OTA in aqueous solution were investigated in a wide range of $\mathrm{pH}$ to provide useful information for further toxicological studies of one of the most dangerous and diffused natural toxins. The $\mathrm{p} K_{\mathrm{a} 1,2}$ values were determined by two independent techniques. Even though the neutral and the monoanionic OTA absorb at the same wavelength, $\mathrm{p} K_{\mathrm{a} 1}$ was estimated by UV-Vis spectrophotometry, on the basis of the molar absorptivity, and by fluorescence spectroscopy using a 3-way chemometric approach. Thanks to the different absorption wavelengths of the monoanionic and dianionic forms of OTA, $\mathrm{p} K_{\mathrm{a} 2}$ was obtained with higher accuracy. $\mathrm{p} K_{\mathrm{a} 1}$ and $\mathrm{p} K_{\mathrm{a} 2}$ were estimated 4.4 and 7.09 (fit uncertainty 0.1 and 0.01 , respectively) by UV-Vis spectrophotometry and 4.2 and 7.0 (fit uncertainty 0.9 and 0.4 , respectively) by fluorescence spectroscopy, showing consistency between the results.

For the first time, OTA degradation was thoroughly studied by fluorescence spectroscopy assisted by DFT calculations for the identification of the most stable reaction products. In alkaline environment, the excitation-emission matrices highlighted that over time, the dianionic OTA undergoes some degradation reactions that lead to (i) the OTA derivative with the hydrolyzed lactone ring and then (ii) to the OT $\alpha$ derivative with the hydrolyzed lactone ring. Both these forms are less toxic than OTA. ${ }^{28}$ In order to verify the conclusion of the degradation process, the OTA reaction product, OT $\alpha$, was compared with a standard OT $\alpha$ solution, as no EEM reference was found in the literature for this molecule. However, the reversibility studies showed that the species obtained upon re-acidification depend on those initially present under alkaline conditions, that can differ depending on $\mathrm{pH}$ and storage time. Dianionic and trianionic forms of OTA at $\mathrm{pH} 12.5$ in fresh solution return to the neutral form of OTA when the acidic conditions are quickly restored, representing again a hazard to humans. Conversely, OT $\alpha$ with the hydrolyzed ring does not return to the neutral OTA, but only to the neutral OT $\alpha$. Irreversible fragmentation can be completed only after a very long time (more than one week) in strongly basic solutions. These conditions are necessary to achieve an effective OTA inactivation.

The theoretical modelistic study suggests a reaction pathway that matches experimental data and facilitates their interpretation. Also, the computed absorption maxima of the intermediates along the suggested pathway resulted consistent with experiments. The possibility to prepare stable aqueous solutions containing specific forms of OTA is useful in view of further toxicological studies specific for each OTA form.

\section{Conflicts of interest}

There are no conflicts to declare.

\section{Acknowledgements}

This research was funded by Progetto Premiale d4l 2014, "Cibo e Salute" by INRIM and by local funding of the University of
Torino. The authors thank Danilo Serazio (INRIM) for the necessary modifications of the devices for the fluorescence measurements.

\section{References}

1 H. J. Lee and D. Ryu, J. Agric. Food Chem., 2017, 65, 70347051.

2 L. Covarelli, G. Beccari, A. Marini and L. Tosi, Food Control, 2012, 26, 347-356.

3 A. Dalcero, C. Magnoli, C. Hallak, S. M. Chiacchiera, G. Palacio and C. A. R. Rosa, Food Addit. Contam., 2002, 19, 1065-1072.

4 A. Prelle, D. Spadaro, A. Garibaldi and M. L. Gullino, Food Control, 2014, 39, 192-197.

5 S. Z. Iqbal, Z. Mehmood, M. R. Asi, M. Shahid, M. Sehar and N. Malik, J. Food Saf., 2018, 38, e12462.

6 World Health Organization, Some naturally occurring substances: food items and constituents, heterocyclic aromatic amines and mycotoxins, Ochratoxin A, IARC Monographs on the evaluation of carcinogenc risks to human, International Agency for Research on Cancer, 1993, vol. 56, pp. 489-521.

7 Eur. Food Saf. Agency, EFSA J., 2006, 4, 1-56, DOI: 10.2903/ j.efsa.2006.365.

8 Eur. Food Saf. Agency, EFSA J., 2010, 8, 1627-1665, DOI: 10.2903/j.efsa.2010.1627.

9 N. J. Mitchell, C. Chen, J. D. Palumbo, A. Bianchini, J. Cappozzo, J. Stratton, D. Ryu and F. Wu, Food Chem. Toxicol., 2017, 100, 265-273.

10 S. C. Duarte, C. M. Lino and A. Pena, Food Addit. Contam., Part A, 2010, 27, 1440-1450.

11 Commission Regulation (EC) no 1881/2006 setting maximum levels for certain contaminants in foodstuffs,http://ec.europa.eu/food/food/chemicalsafety/ contaminants/legisl_en.htm.

12 N. W. Turner, S. Subrahmanyam and S. A. Piletsky, Anal. Chim. Acta, 2009, 632, 168-180.

13 A. Kaushik, S. K. Arya, A. Vasudev and S. Bhansali, Open J. Appl. Biosens., 2013, 02, 1-11.

14 L. Anfossi, C. Giovannoli and C. Baggiani, Curr. Opin. Biotechnol., 2016, 37, 120-126.

15 Á. Molinero-Fernández, A. Jodra, M. Moreno-Guzmán, M. Á. López and A. Escarpa, Chem.-Eur. J., 2018, 24, 71727176.

16 M. L. Savastano, I. Losito and S. Pati, Food Control, 2016, 68, 391-398.

17 F. Chen, C. Luan, L. Wang, S. Wang and L. Shao, J. Sci. Food Agric., 2016, 97, 1805-1810.

18 C. Giovannoli, C. Passini, F. Di Nardo, L. Anfossi and C. Baggiani, J. Agric. Food Chem., 2014, 62, 5220-5225.

19 L. González-Osnaya, J. M. Soriano, J. C. Moltó and J. Mañes, Food Chem., 2008, 108, 272-276.

20 L. Monaci and F. Palmisano, Anal. Bioanal. Chem., 2004, 378, 96-103.

21 F. Berthiller, C. Brera, M. H. Iha, R. Krska, V. M. T. Lattanzio, S. MacDonald, R. J. Malone, C. Maragos, M. Solfrizzo, 
M. Stranska-Zachariasova, J. Stroka and S. A. Tittlemier, World Mycotoxin J., 2017, 10, 5-29.

22 F. Malir, V. Ostry, A. Pfohl-Leszkowicz, J. Malir and J. Toman, Toxins, 2016, 8, 191.

23 A. E. el Khoury and A. Atoui, Toxins, 2010, 2, 461-493.

24 S. Uchiyama, Y. Saito and M. Uchiyama, Food Hyg. Saf. Sci., 1985, 26, 651-657.

25 I. G. Gillman, T. N. Clark and R. A. Manderville, Chem. Res. Toxicol., 1999, 12, 1066-1076.

26 H. Xiao, S. Madhyastha, R. R. Marquardt, S. Li, J. K. Vodela, A. A. Frohlich and B. W. Kemppainen, Toxicol. Appl. Pharmacol., 1996, 137, 182-192.

27 R. R. Marquardt and A. A. Frohlich, J. Anim. Sci., 1992, 70, 3968-3988.

28 F. Sun Chu, I. Noh and C. C. Chang, Life Sci., 1972, 11, 503508.

29 F. S. Chu, Arch. Biochem. Biophys., 1971, 147, 359-366.

30 M. J. Pitout, Toxicol. Appl. Pharmacol., 1968, 13, 299-306.

31 F. S. Chu and B. J. Wilson, CRC Crit. Rev. Toxicol., 1973, 2, 499-524.

32 Y. V. Il'ichev, J. L. Perry, R. A. Manderville, C. F. Chignell and J. D. Simon, J. Phys. Chem. B, 2001, 105, 11369-11376.

33 C. De Stefano, P. Princi, C. Rigano, C. Van de Wiele and S. Sammartano, Ann. Chim., 1987, 77, 643-675.

34 P. Gans, A. Sabatini and A. Vacca, Talanta, 1996, 43, 17391753.

35 R. Karoui and C. Blecker, Food Bioprocess Technol., 2011, 4, 364-386.

36 R. A. Harshman, UCLA Working Papers in Phonetics, 1970, 16, 1-84.

37 C. M. Andersen and R. Bro, J. Chemom., 2003, 17, 200-215.

38 S. Leurgans and R. T. Ross, Stat. Sci., 1992, 7, 289-310.

39 R. T. Ross and S. Leurgans, Component resolution using multilinear models, in Methods in Enzymology, Academic Press, 1995, pp. 679-700, DOI: 10.1016/0076-6879(95) 46029-2.

40 Joint Committee for Guides in Metrology, JCGM 101: Evaluation of Measurement Data-Supplement 1 to the 'Guide to the Expression of Uncertainty in Measurement' Propagation of Distributions Using a Monte Carlo Method, 2008.

41 J. A. Pople, P. M. W. Gill and B. G. Johnson, Chem. Phys. Lett., 1992, 199, 557-560.

42 H. B. Schlegel, in Computational Theoretical Organic Chemistry, ed. I. G. Csizmadia and R. Daudel, Springer, Netherlands, Dordrecht, 1981, pp. 129-159.

43 H. B. Schlegel, J. Chem. Phys., 1982, 77, 3676-3681.

44 H. B. Schlegel, J. S. Binkley and J. A. Pople, J. Chem. Phys., 1984, 80, 1976-1981.

45 H. B. Schlegel, J. Comput. Chem., 1982, 3, 214-218.

46 R. G. Parr and W. Yang, Density-Functional Theory of Atoms and Molecules, Oxford University Press, 1989.

47 J.-D. Chai and M. Head-Gordon, Phys. Chem. Chem. Phys., 2008, 10, 6615-6620.

48 A. D. McLean and G. S. Chandler, J. Chem. Phys., 1980, 72, 5639-5648.
49 R. Krishnan, J. S. Binkley, R. Seeger and J. A. Pople, J. Chem. Phys., 1980, 72, 650-654.

50 A. V. Marenich, C. J. Cramer and D. G. Truhlar, J. Phys. Chem. $B, 2009$, 113, 6378-6396.

51 R. E. Skyner, J. L. McDonagh, C. R. Groom, T. Van Mourik and J. B. O. Mitchell, Phys. Chem. Chem. Phys., 2015, 17, 6174-6191.

52 E. Cancès, B. Mennucci and J. Tomasi, J. Chem. Phys., 1997, 107, 3032-3041.

53 R. Gómez-Bombarelli, E. Calle and J. Casado, J. Org. Chem., 2013, 78, 6880-6889.

54 Y. Jin, Y. Zhu and M. Tang, Comput. Theor. Chem., 2011, 963, 268-272.

55 D. Cheshmedzhieva, S. Ilieva, B. Hadjieva and B. Galabov, J. Phys. Org. Chem., 2009, 22, 619-631.

56 R. Bauernschmitt and R. Ahlrichs, Chem. Phys. Lett., 1996, 256, 454-464.

57 M. E. Casida, C. Jamorski, K. C. Casida and D. R. Salahub, J. Chem. Phys., 1998, 108, 4439-4449.

58 G. Scalmani, M. J. Frisch, B. Mennucci, J. Tomasi, R. Cammi and V. Barone, J. Chem. Phys., 2006, 124, 094107.

59 R. E. Stratmann, G. E. Scuseria and M. J. Frisch, J. Chem. Phys., 1998, 109, 8218-8224.

60 A. J. Cohen and N. C. Handy, Mol. Phys., 2001, 99, 607-615. 61 P. Krawczyk, J. Mol. Model., 2015, 21, 118.

62 M. H. Khalilian, S. Mirzaei and A. A. Taherpour, J. Mol. Model., 2016, 22, 270.

63 M. J. Frisch, G. W. Trucks, H. B. Schlegel, G. E. Scuseria, M. A. Robb, J. R. Cheeseman, G. Scalmani, V. Barone, B. Mennucci, G. A. Petersson, H. Nakatsuji, M. Caricato, X. Li, H. P. Hratchian, A. F. Izmaylov, J. Bloino, G. Zheng, J. L. Sonnenberg, M. Hada, M. Ehara, K. Toyota, R. Fukuda, J. Hasegawa, M. Ishida, T. Nakajima, Y. Honda, O. Kitao, H. Nakai, T. Vreven, J. A. Montgomery Jr, J. E. Peralta, F. Ogliaro, M. Bearpark, J. J. Heyd, E. Brothers, K. N. Kudin, V. N. Staroverov, R. Kobayashi, J. Normand, K. Raghavachari, A. Rendell, J. C. Burant, S. S. Iyengar, J. Tomasi, M. Cossi, N. Rega, J. M. Millam, M. Klene, J. E. Knox, J. B. Cross, V. Bakken, C. Adamo, J. Jaramillo, R. Gomperts, R. E. Stratmann, O. Yazyev, A. J. Austin, R. Cammi, C. Pomelli, J. W. Ochterski, R. L. Martin, K. Morokuma, V. G. Zakrzewski, G. A. Voth, P. Salvador, J. J. Dannenberg, S. Dapprich, A. D. Daniels, Ö. Farkas, J. B. Foresman, J. V Ortiz, J. Cioslowski and D. J. Fox, Gaussian 09, Revision D.01, Gaussian, Inc., Wallingford CT, 2016.

64 G. Schaftenaar and J. H. Noordik, J. Comput.-Aided Mol. Des., 2000, 14, 123-134.

65 R. Verrone, L. Catucci, P. Cosma, P. Fini, A. Agostiano, V. Lippolis and M. Pascale, J. Inclusion Phenom. Macrocyclic Chem., 2007, 57, 475-479.

66 A. Casale, P. G. Daniele, A. De Robertis and S. Sammartano, Ann. Chim., 1988, 78, 249-260.

67 I. Bazin, V. Faucet-Marquis, M. C. Monje, M. El Khoury, J. L. Marty and A. Pfohl-Leszkowicz, Toxins, 2013, 5, 2324-2340. 68 J. Christensen, L. Nørgaard, R. Bro and S. B. Engelsen, Chem. Rev., 2006, 106, 1979-1994. 